\title{
National, Regional, State, and Selected Local Area Vaccination Coverage Among Adolescents Aged 13-17 Years — United States, 2019
}

\author{
Laurie D. Elam-Evans ${ }^{1}$, PhD; David Yankey, $\mathrm{PhD}^{1}$; James A. Singleton, $\mathrm{PhD}^{1}$; Natalie Sterrett, $\mathrm{MPH}^{1,2}$; Lauri E. Markowitz, MD ${ }^{3}$;
} Charnetta L. Williams, MD ${ }^{1}$; Benjamin Fredua, MS ${ }^{1,4}$; Lucy McNamara, PhD 5 ; Shannon Stokley, $\mathrm{DrPH}^{1}$

Three vaccines are recommended by the Advisory Committee on Immunization Practices (ACIP) for routine vaccination of adolescents aged 11-12 years to protect against 1) pertussis; 2) meningococcal disease caused by types $\mathrm{A}, \mathrm{C}, \mathrm{W}$, and $\mathrm{Y}$; and 3) human papillomavirus (HPV)-associated cancers (1). At age 16 years, a booster dose of quadrivalent meningococcal conjugate vaccine (MenACWY) is recommended. Persons aged 16-23 years can receive serogroup $B$ meningococcal vaccine (MenB), if determined to be appropriate through shared clinical decision-making. CDC analyzed data from the 2019 National Immunization Survey-Teen (NIS-Teen) to estimate vaccination coverage among adolescents aged 13-17 years in the United States.* Coverage with $\geq 1$ dose of HPV vaccine increased from $68.1 \%$ in 2018 to $71.5 \%$ in 2019 , and the percentage of adolescents who were up to date ${ }^{\dagger}$ with the HPV vaccination series (HPV UTD) increased from $51.1 \%$ in 2018 to $54.2 \%$

\footnotetext{
*Eligible participants were born during January 2001-February 2007. Tetanus toxoid, reduced diphtheria toxoid, and acellular pertussis vaccine (Tdap) represents coverage with $\geq 1$ Tdap dose at age $\geq 10$ years. Meningococcal conjugate vaccine (MenACWY) represents coverage with the quadrivalent meningococcal conjugate vaccine or meningococcal-unknown type vaccine. Human papillomavirus (HPV) vaccination coverage includes receipt of any $\mathrm{HPV}$ vaccine and does not distinguish between nine-valent $(9 \mathrm{vHPV})$, quadrivalent $(4 \mathrm{vHPV})$, or bivalent $(2 \mathrm{vHPV})$ vaccines. Some adolescents might have received more than the two or three recommended HPV vaccine doses. Estimates for hepatitis A, hepatitis B, and measles, mumps, and rubella vaccines represent coverage based on the catch-up schedule for adolescents who are not up to date with these vaccinations. Except as noted, coverage estimates for $\geq 1$ and $\geq 2$ varicella vaccine doses were obtained among adolescents with no history of varicella disease. Influenza vaccination coverage data are not included in this report but are available online at https:// www.cdc.gov/flu/fluvaxview/index.htm.

$\dagger$ Adolescents were considered to be up to date with HPV vaccination if they had received $\geq 3$ doses, or if each of the following applied: 1) they had received 2 doses; 2) the first dose was received before their 15th birthday; and 3) the difference between dates of first and second doses was $\geq 5$ months minus 4 days, the absolute minimum interval between the first and second doses. https:// www.cdc.gov/vaccines/programs/iis/cdsi.html.
}

in 2019. Both HPV vaccination coverage measures improved among females and males. An increase in adolescent coverage with $\geq 1$ dose of MenACWY (from 86.6\% in 2018 to $88.9 \%$ in 2019) also was observed. Among adolescents aged 17 years, $53.7 \%$ received the booster dose of MenACWY in 2019, not statistically different from $50.8 \%$ in $2018 ; 21.8 \%$ received $\geq 1$ dose of MenB, a 4.6 percentage point increase from $17.2 \%$ in 2018. Among adolescents living at or above the poverty level, $\$$

\section{INSIDE}

1117 Overdose Education and Naloxone Distribution Within Syringe Service Programs — United States, 2019

1122 Disparities in Incidence of COVID-19 Among Underrepresented Racial/Ethnic Groups in Counties Identified as Hotspots During June 5-18, 2020 - 22 States, February-June 2020

1127 Trends in Number and Distribution of COVID-19 Hotspot Counties - United States, March 8July 15, 2020

1133 Racial and Ethnic Disparities Among COVID-19 Cases in Workplace Outbreaks by Industry Sector - Utah, March 6-June 5, 2020

1139 Mass Testing for SARS-CoV-2 in 16 Prisons and Jails Six Jurisdictions, United States, April-May 2020

1144 Notes from the Field: COVID-19 Prevention Practices in State Prisons - Puerto Rico, 2020

1145 QuickStats

Continuing Education examination available at https://www.cdc.gov/mmwr/mmwr_continuingEducation.html

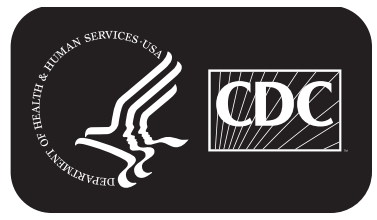

U.S. Department of Health and Human Services Centers for Disease Control and Prevention 
those living outside a metropolitan statistical area (MSA) had lower coverage with $\geq 1$ dose of MenACWY and with $\geq 1$ $H P V$ vaccine dose, and a lower percentage were HPV UTD, compared with those living in MSA principal cities. In early 2020, the coronavirus disease 2019 (COVID-19) pandemic changed the way health care providers operate and provide routine and essential services. An examination of Vaccines for Children (VFC) provider ordering data showed that vaccine orders for HPV vaccine; tetanus toxoid, reduced diphtheria toxoid, and acellular pertussis vaccine (Tdap); and MenACWY decreased in mid-March when COVID-19 was declared a national emergency (Supplementary Figure 1, https://stacks. cdc.gov/view/cdc/91795). Ensuring that routine immunization services for adolescents are maintained or reinitiated is essential to continuing progress in protecting persons and communities from vaccine-preventable diseases and outbreaks.

\footnotetext{
\$Adolescents were classified as being below the federal poverty level if their total family income was less than the federal poverty level specified for the applicable family size and number of children aged $<18$ years. All others were classified as at or above the poverty level (https://www.census.gov/data/tables/time-series/ demo/income-poverty/historical-poverty-thresholds.html). Poverty status was unknown for 657 adolescents.

Metropolitan statistical area (MSA) status was determined from household reported city and county of residence and was grouped into three categories: MSA principal city, MSA nonprincipal city, and non-MSA. MSA and MSA principal city were as defined by the U.S. Census Bureau (https://www.census. gov/programs-surveys/metro-micro.html). Non-MSA areas include urban populations not located within an MSA and completely rural areas.
}

NIS-Teen is a random-digit-dial telephone survey** conducted annually to monitor vaccination coverage among adolescents aged 13-17 years in the 50 states, the District of Columbia, selected local areas, and selected U.S. territories. ${ }^{\dagger \dagger}$ Sociodemographic information is collected during the telephone interview with a parent or guardian, and a request is made for consent to contact the adolescent's vaccination provider(s). If consent is obtained, a questionnaire is mailed to the vaccination provider(s) to request the adolescent's vaccination history. Vaccination coverage estimates are determined from these provider-reported immunization records. This report provides vaccination coverage estimates on 18,788 adolescents aged 13-17 years. ${ }^{\$ \$}$ The overall Council of American

\footnotetext{
** All identified cellular-telephone households were eligible for interview. Sampling weights were adjusted for single frame (cellular telephone), nonresponse, noncoverage, and overlapping samples of mixed telephone users. A description of NIS-Teen single-frame survey methodology and its effect on reported vaccination estimates is available at https://www.cdc.gov/vaccines/ imz-managers/coverage/teenvaxview/pubs-presentations/dual-to-single-frameteen.html.

$\dagger \dagger$ Local areas that received federal immunization funds under Section 317 of the Public Health Service Act were sampled separately. Those included Chicago, Illinois; New York, New York; Philadelphia County, Pennsylvania; Bexar County, Texas; and Houston, Texas. Two local areas were oversampled in 2019: Dallas County, Texas, and El Paso County, Texas. Three territories were sampled separately in 2019: Guam, Puerto Rico, and the U.S. Virgin Islands.

$\$ \$$ Adolescents from Guam $(\mathrm{n}=278)$, Puerto Rico $(\mathrm{n}=216)$, and U.S. Virgin Island $(\mathrm{n}=218)$ were excluded from the national estimates.
}

The MMWR series of publications is published by the Center for Surveillance, Epidemiology, and Laboratory Services, Centers for Disease Control and Prevention (CDC), U.S. Department of Health and Human Services, Atlanta, GA 30329-4027.

Suggested citation: [Author names; first three, then et al., if more than six.] [Report title]. MMWR Morb Mortal Wkly Rep 2020;69:[inclusive page numbers]

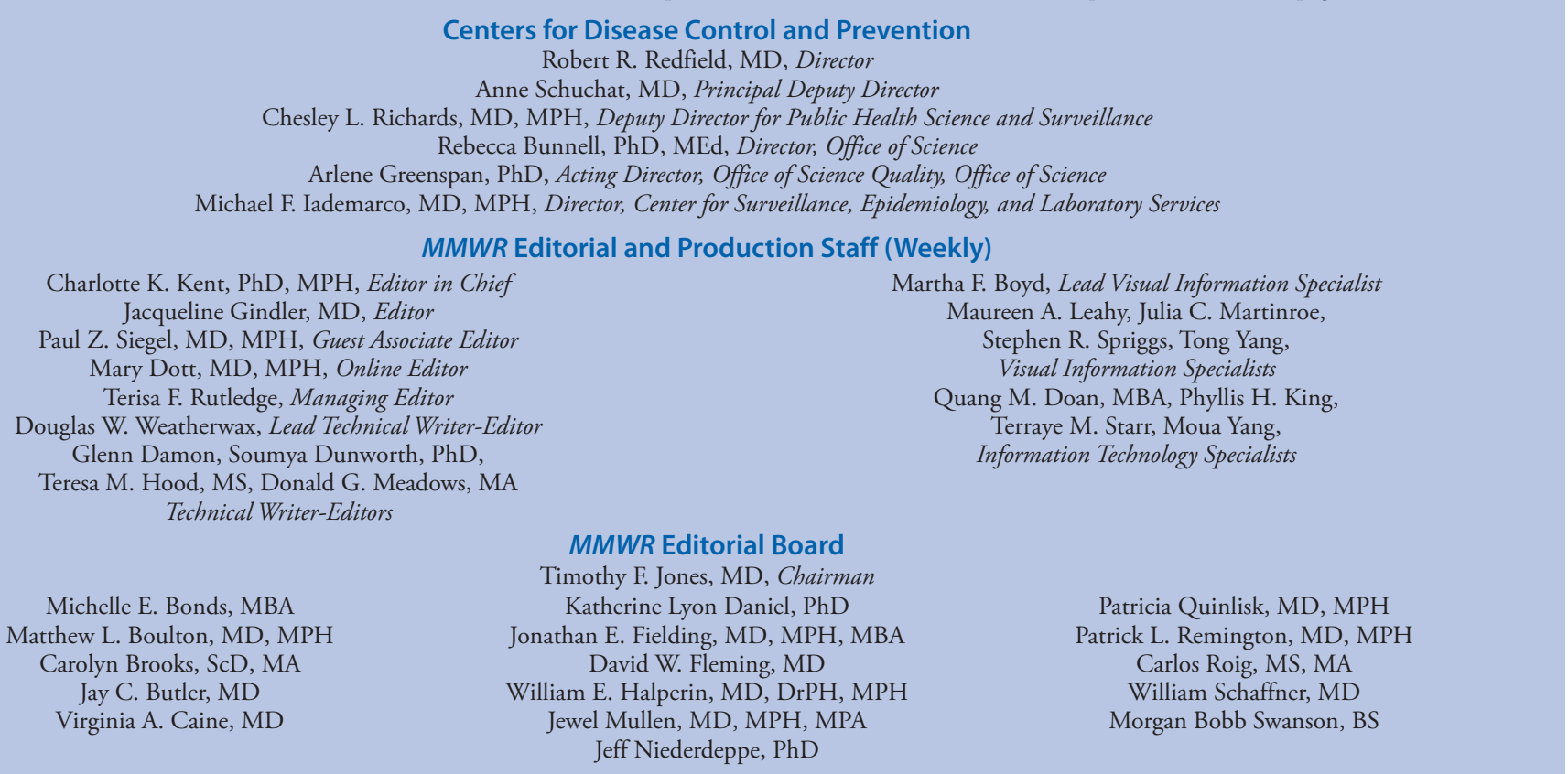


Survey Research Organizations (CASRO) 99 response rate was $19.7 \%$, and $44.0 \%$ of adolescents for whom household interviews were completed had adequate provider data.

Data were weighted and analyzed to account for the complex sampling design. ${ }^{* *}$ T-tests were used to assess vaccination coverage differences between sociodemographic subgroups. P-values $<0.05$ were considered statistically significant. All analyses were conducted using SAS-callable SUDAAN (version 11; RTI International).

\section{National Vaccination Coverage}

In 2019, 71.5\% of adolescents aged 13-17 years had received $\geq 1$ dose of HPV vaccine, and $54.2 \%$ had completed the HPV vaccination series and were considered HPV UTD (Table 1, Figure). Increases from 2018 in $\geq 1$ dose HPV vaccine coverage and HPV UTD status were observed for females and for males. Coverage with $\geq 1$ dose of MenACWY increased by 2.3 percentage points to $88.9 \%$. Coverage with $\geq 2 \mathrm{MenACWY}$ doses among adolescents aged 17 years was $53.7 \%$, similar to that in 2018 (50.8\%). Coverage with $\geq 1$ dose of MenB among adolescents aged 17 years increased from $17.2 \%$ in 2018 to $21.8 \%$ in 2019 . Coverage with $\geq 1$ dose of Tdap remained stable and high (90.2\%). Coverage exceeded $90 \%$ for $\geq 2$ doses measles, mumps, and rubella vaccine (MMR), $\geq 3$ doses of hepatitis $\mathrm{B}$ vaccine, and $\geq 1$ and $\geq 2$ doses of varicella vaccine among adolescents without a history of varicella disease. ${ }^{\dagger \dagger}$

\section{Vaccination Coverage by Selected Characteristics}

In 2019, compared with adolescents living in MSA principal cities, coverage with $\geq 1$ dose of HPV vaccine among those living in non-MSA areas was 9.6 percentage points lower, the percentage who were HPV UTD was 9.8 percentage points lower, and coverage with $\geq 1$ dose of MenACWY was 5.1 percentage points lower. These disparities were only observed among adolescents living at or above the poverty level (Table 2). Coverage with all vaccine doses recommended for adolescents varied by jurisdiction, with differences ranging from 15 percentage points for $\geq 1$ Tdap dose to 48.4 percentage

\footnotetext{
99 The CASRO response rate is the product of three other rates: 1) the resolution rate (the proportion of telephone numbers that can be identified as either for business or residence), 2) the screening rate (the proportion of qualified households that complete the screening process), and 3) the cooperation rate (the proportion of contacted eligible households for which a completed interview is obtained).

*** The NIS-Teen methodology for weighting and synthesizing provider-reported vaccination histories has been previously described. https://www.cdc.gov/ vaccines/imz-managers/nis/downloads/NIS-Teen-PUF18-DUG.pdf.

††† Hepatitis A, hepatitis B, varicella, and measles, mumps, and rubella vaccines are considered childhood vaccinations and are recommended for adolescents who are not up to date with these vaccinations. Estimates in this report include those who might have received vaccinations on-time or as catch-up.
}

points for being HPV UTD (Supplementary Table, https:// stacks.cdc.gov/view/cdc/91797). Differences were observed in vaccination coverage by race and ethnicity $\$ \$ \$$ and by health insurance status. 999

\section{Trends in HPV Vaccination by Birth Cohort}

HPV vaccination initiation by age 13 years increased an average of 5.3 percentage points for each consecutive birth year, from $19.9 \%$ among adolescents born in 1998 to $62.6 \%$ among those born in 2006 (Supplementary Figure 2, https:// stacks.cdc.gov/view/cdc/91796). Being HPV UTD by age 13 years increased an average of 3.4 percentage points for each consecutive birth year, from $8.0 \%$ among adolescents born in 1998 to $35.5 \%$ among those born in 2006 .

\section{Discussion}

In 2019, coverage with HPV vaccine and with MenACWY improved compared with coverage in 2018. Improvements in $\geq 1$ dose HPV and HPV UTD vaccination coverage were observed among females and males. In addition, more teens began HPV vaccination on time (by age 13 years) in 2019, suggesting that more parents are making the decision to protect their teens against HPV-associated cancers. Efforts from federal, state, and other stakeholders to prioritize HPV vaccination among adolescents, and reducing the number of recommended HPV vaccine doses from a 3-dose to a 2-dose series, (2) likely contributed to these improvements. Coverage with $\geq 1$ dose of MenACWY increased to $88.9 \%$; coverage with $\geq 2$ doses remained low at $53.7 \%$, indicating that continued efforts are needed to improve receipt of the booster dose.

Despite progress in adolescent HPV vaccination and MenACWY coverage, disparities remain; all adolescents are not equally protected against vaccine-preventable diseases. As in previous years, compared with adolescents living in MSA principal cities, HPV UTD status and coverage with $\geq 1$ dose each of HPV vaccine and MenACWY continue to be lower among adolescents in non-MSA areas (3). However, these geographic disparities were present only for adolescents at or above the poverty level in 2019. This finding is consistent with another study that found socioeconomic status to be a moderating factor in the association between $\mathrm{HPV}$ vaccination and MSA (4). The lack of an MSA disparity among adolescents below the poverty level might reflect the access that low-income

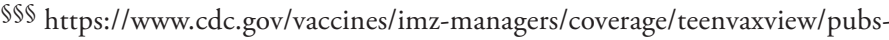
presentations/NIS-teen-vac-coverage-estimates-2019-tables.html\#table-01

$999 \mathrm{https} / /$ www.cdc.gov/vaccines/imz-managers/coverage/teenvaxview/pubspresentations/NIS-teen-vac-coverage-estimates-2019-tables.html\#table-02.
} 
TABLE 1. Estimated vaccination coverage with selected vaccines and doses among adolescents aged $13-17^{*}$ years, by age at interview National Immunization Survey-Teen (NIS-Teen), United States, 2019

\begin{tabular}{|c|c|c|c|c|c|c|c|}
\hline \multirow[b]{2}{*}{ Vaccine } & \multicolumn{5}{|c|}{$\begin{array}{c}\text { Age at interview, yrs } \\
\%(95 \% \mathrm{Cl})^{\dagger}\end{array}$} & \multicolumn{2}{|c|}{$\begin{array}{c}\text { Total } \\
\%(95 \% \mathrm{Cl})^{\dagger}\end{array}$} \\
\hline & $\begin{array}{c}13 \\
(n=3,927)\end{array}$ & $\begin{array}{c}14 \\
(n=4,007)\end{array}$ & $\begin{array}{c}15 \\
(n=3,753)\end{array}$ & $\begin{array}{c}16 \\
(n=3,753)\end{array}$ & $\begin{array}{c}17 \\
(n=3,348)\end{array}$ & $\begin{array}{c}2019 \\
(n=18,788)\end{array}$ & $\begin{array}{c}2018 \\
(n=18,700)\end{array}$ \\
\hline $\begin{array}{l}\operatorname{Tdap}^{\S} \geq 1 \text { dose } \\
\text { MenACWY** }\end{array}$ & $89.0(87.2-90.6)$ & $91.8(89.6-93.5)^{9}$ & $91.4(89.6-92.9)$ & $89.5(87.4-91.3)$ & $88.9(85.3-91.7)$ & $90.2(89.2-91.1)$ & $88.9(88.0-89.7)$ \\
\hline $\begin{array}{l}\geq 1 \text { dose } \\
\geq 2 \text { doses }{ }^{\S}\end{array}$ & $\begin{array}{c}87.7(86.0-89.3) \\
\text { NA }\end{array}$ & $\begin{array}{c}91.2(89.6-92.5)^{\natural} \\
\text { NA }\end{array}$ & $\begin{array}{c}88.3(86.2-90.1) \\
\text { NA }\end{array}$ & $\begin{array}{c}88.3(85.8-90.4) \\
\text { NA }\end{array}$ & $\begin{array}{l}88.9(85.9-91.4) \\
53.7(49.9-57.4)\end{array}$ & $\begin{array}{l}88.9(88.0-89.8)^{\dagger+} \\
53.7(49.9-57.4)\end{array}$ & $\begin{array}{l}86.6(85.6-87.5) \\
50.8(47.7-53.8)\end{array}$ \\
\hline \multicolumn{8}{|l|}{ HPVๆๆๆ vaccine } \\
\hline $\begin{array}{l}\geq 1 \text { dose } \\
\text { HPV UTD*** }\end{array}$ & $\begin{array}{l}66.9(64.1-69.6) \\
45.3(42.1-48.5)\end{array}$ & $\begin{array}{l}73.6(70.8-76.3)^{\natural} \\
52.2(48.6-55.8)^{\natural}\end{array}$ & $\begin{array}{l}72.1(69.1-75.0)^{\natural} \\
58.6(55.3-61.8)^{\natural}\end{array}$ & $\begin{array}{l}71.2(68.1-74.0)^{9} \\
57.6(54.4-60.8)^{9}\end{array}$ & $\begin{array}{l}73.1(69.7-76.3)^{\natural} \\
57.1(53.2-60.8)^{\natural}\end{array}$ & $\begin{array}{l}71.5(70.1-72.8)^{\dagger+} \\
54.2(52.7-55.8)^{\dagger+}\end{array}$ & $\begin{array}{l}68.1(66.8-69.3) \\
51.1(49.8-52.5)\end{array}$ \\
\hline $\begin{array}{l}\text { Females } \\
\geq 1 \text { dose } \\
\text { HPV UTD }\end{array}$ & $\begin{array}{l}68.4(64.0-72.5) \\
48.9(43.9-53.9)\end{array}$ & $\begin{array}{l}75.1(71.4-78.5)^{\natural} \\
53.0(48.0-57.9)\end{array}$ & $\begin{array}{l}75.6(71.6-79.2)^{\natural} \\
61.6(57.0-66.0)^{\natural}\end{array}$ & $\begin{array}{l}71.9(67.1-76.3) \\
61.5(56.8-66.0)^{9}\end{array}$ & $\begin{array}{l}74.9(70.0-79.2)^{\natural} \\
59.2(53.6-64.5)^{\natural}\end{array}$ & $\begin{array}{l}73.2(71.3-75.0)^{t \dagger} \\
56.8(54.6-59.0)^{t+}\end{array}$ & $\begin{array}{l}69.9(68.1-71.6) \\
53.7(51.8-55.6)\end{array}$ \\
\hline \multicolumn{8}{|l|}{ Males } \\
\hline $\begin{array}{l}\geq 1 \text { dose } \\
\text { HPV UTD }\end{array}$ & $\begin{array}{l}65.4(61.8-68.8) \\
41.5(37.9-45.3)\end{array}$ & $\begin{array}{l}72.2(67.8-76.1)^{9} \\
51.5(46.2-56.7)^{9}\end{array}$ & $\begin{array}{l}68.9(64.3-73.1) \\
55.7(51.1-60.2)^{q}\end{array}$ & $\begin{array}{l}70.4(66.4-74.1) \\
53.9(49.5-58.2)^{q}\end{array}$ & $\begin{array}{l}71.6(66.6-76.1)^{\natural} \\
55.2(49.9-60.4)^{\natural}\end{array}$ & $\begin{array}{l}69.8(67.9-71.7)^{\dagger \dagger} \\
51.8(49.7-53.9)^{\dagger \dagger}\end{array}$ & $\begin{array}{l}66.3(64.6-68.0) \\
48.7(46.8-50.6)\end{array}$ \\
\hline MenB $\geq 1$ dose $^{\dagger+\dagger}$ & NA & NA & NA & NA & $21.8(18.9-24.9)$ & $21.8(18.9-24.9)^{\dagger+}$ & $17.2(14.9-19.9)$ \\
\hline MMR $\geq 2$ doses & $93.0(91.1-94.4)$ & $91.2(88.1-93.5)$ & $93.3(91.7-94.6)$ & $91.2(89.0-92.9)$ & 90.7 (87.5-93.2) & $91.9(90.8-92.8)$ & $91.9(91.2-92.6)$ \\
\hline $\begin{array}{l}\text { Hepatitis A vaccine } \\
\geq 2 \text { doses }{ }^{\S \S}\end{array}$ & $84.1(81.6-86.2)$ & $79.8(76.7-82.6)^{9}$ & $78.1(75.3-80.6)^{\natural}$ & $71.8(68.9-74.5)^{9}$ & $71.9(68.1-75.4)^{9}$ & $77.1(75.8-78.4)^{\dagger \dagger}$ & $73.6(72.4-74.7)$ \\
\hline $\begin{array}{l}\text { Hepatitis B vaccine } \\
\geq 3 \text { doses }\end{array}$ & $92.1(90.1-93.7)$ & $91.6(88.6-93.8)$ & $92.8(91.1-94.2)$ & $90.7(88.5-92.5)$ & $90.8(87.4-93.4)$ & $91.6(90.6-92.6)$ & $92.1(91.3-92.8)$ \\
\hline $\begin{array}{l}\text { Varicella } \\
\text { History of } \\
\text { varicella }\end{array}$ & $6.8(5.4-8.5)$ & $8.4(7.0-10.0)$ & $9.6(8.0-11.4)^{9}$ & $10.4(8.7-12.3)^{9}$ & $10.4(8.8-12.4)^{9}$ & $9.1(8.4-9.9)^{\dagger+}$ & $11.9(11.0-12.7)$ \\
\hline \multicolumn{8}{|c|}{ No history of varicella disease } \\
\hline$\geq 1$ dose vaccine & $96.0(94.9-96.8)$ & $94.7(92.1-96.5)$ & $95.8(94.6-96.7)$ & $94.4(92.3-95.9)$ & $95.0(92.2-96.9)$ & $95.2(94.3-95.9)$ & $94.9(94.3-95.4)$ \\
\hline$\geq 2$ doses vaccine & 91.6 (89.6-93.2) & 91.0 (87.7-93.5) & $92.5(90.9-93.8)$ & 90.1 (87.7-92.0) & $87.8(84.1-90.7)$ & $90.6(89.5-91.7)$ & 89.6 (88.7-90.4) \\
\hline $\begin{array}{l}\text { Varicella disease or } \\
\text { received } \geq 2 \\
\text { varicella vaccine } \\
\text { doses }\end{array}$ & $92.2(90.3-93.7)$ & $91.8(88.7-94.0)$ & $93.2(91.8-94.4)$ & $91.1(88.9-92.9)$ & 89.1 (85.7-91.7) & $91.5(90.4-92.4)$ & $90.8(90.0-91.6)$ \\
\hline
\end{tabular}

Abbreviations: $\mathrm{Cl}=$ confidence interval; $\mathrm{HPV}=$ human papillomavirus; Men $\mathrm{ACWY}=$ quadrivalent meningococcal conjugate vaccine; Men $\mathrm{B}=$ serogroup $\mathrm{B}$ meningococcal vaccine; MMR = measles, mumps, and rubella vaccine; NA = not applicable; Tdap = tetanus toxoid, reduced diphtheria toxoid, and acellular pertussis vaccine; UTD = up-to-date.

* Adolescents $(\mathrm{N}=18,788)$ in the 2019 NIS-Teen were born during January 2001-February 2007.

† Estimates with $95 \% \mathrm{Cls}>20$ might not be reliable.

$\S$ Includes percentages receiving Tdap at age $\geq 10$ years.

१ Statistically significant difference $(p<0.05)$ in estimated vaccination coverage by age; reference group was adolescents aged 13 years.

** Includes percentages receiving MenACWY or meningococcal-unknown type vaccine.

t+ Statistically significant difference $(p<0.05)$ compared with 2018 NIS-Teen estimates.

$\S \S \geq 2$ doses of MenACWY or meningococcal-unknown type vaccine. Calculated only among adolescents aged 17 years at interview. Does not include adolescents who received 1 dose of MenACWY at age $\geq 16$ years.

१ๆ HPV vaccine, nine-valent (9vHPV), quadrivalent (4vHPV), or bivalent (2vHPV). For $\geq 1$ dose and HPV UTD measures, percentages are reported among females and males combined $(\mathrm{N}=18,788)$ and for females only $(\mathrm{N}=8,916)$ and males only $(\mathrm{N}=9,872)$.

*** HPV UTD includes those with $\geq 3$ doses, and those with 2 doses when the first HPV vaccine dose was initiated before age 15 years and there was at least 5 months minus 4 days between the first and second dose. This update to the HPV recommendation occurred in December of 2016.

${ }^{++\dagger} \geq 1$ dose of MenB, administered, based on individual clinical decision; calculated only among adolescents aged 17 years at interview.

$\S \S \S$ In July 2020, ACIP revised recommendations for hepatitis A vaccination to include catch-up vaccination for children and adolescents aged 2-18 years who have not previously received hepatitis A vaccine at any age (http://dx.doi.org/10.15585/mmwr.rr6905a1).

กศศ ถ By parent/guardian report or provider records.

adolescents have to the VFC program****; previous studies have reported higher HPV vaccination coverage rates among adolescents living below the poverty level $(5,6)$. Reasons for the MSA disparity among higher socioeconomic status adolescents are less clear but might be an indicator of lower vaccine confidence. More work is needed to understand the relationship
**** Children aged $\leq 18$ years who are Medicaid-eligible, uninsured, or American Indian/Alaska Native (as defined by the Indian Health Care Improvement Act) are eligible to receive vaccines from providers through the Vaccines for Children (VFC) program. Children categorized as "underinsured" (because their health plans do not include coverage for recommended vaccinations) are eligible to receive VFC vaccines if they are served by a rural health clinic or federally qualified health center or under an approved deputization agreement. https://www.cdc.gov/vaccines/programs/vfc/ providers/eligibility.html. 
FIGURE. Estimated vaccination coverage with selected vaccines and doses* among adolescents aged 13-17 years, by survey year and Advisory

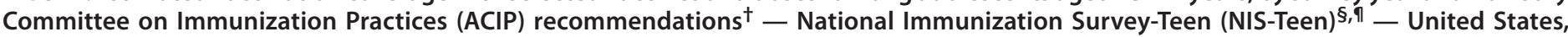
2006-2019

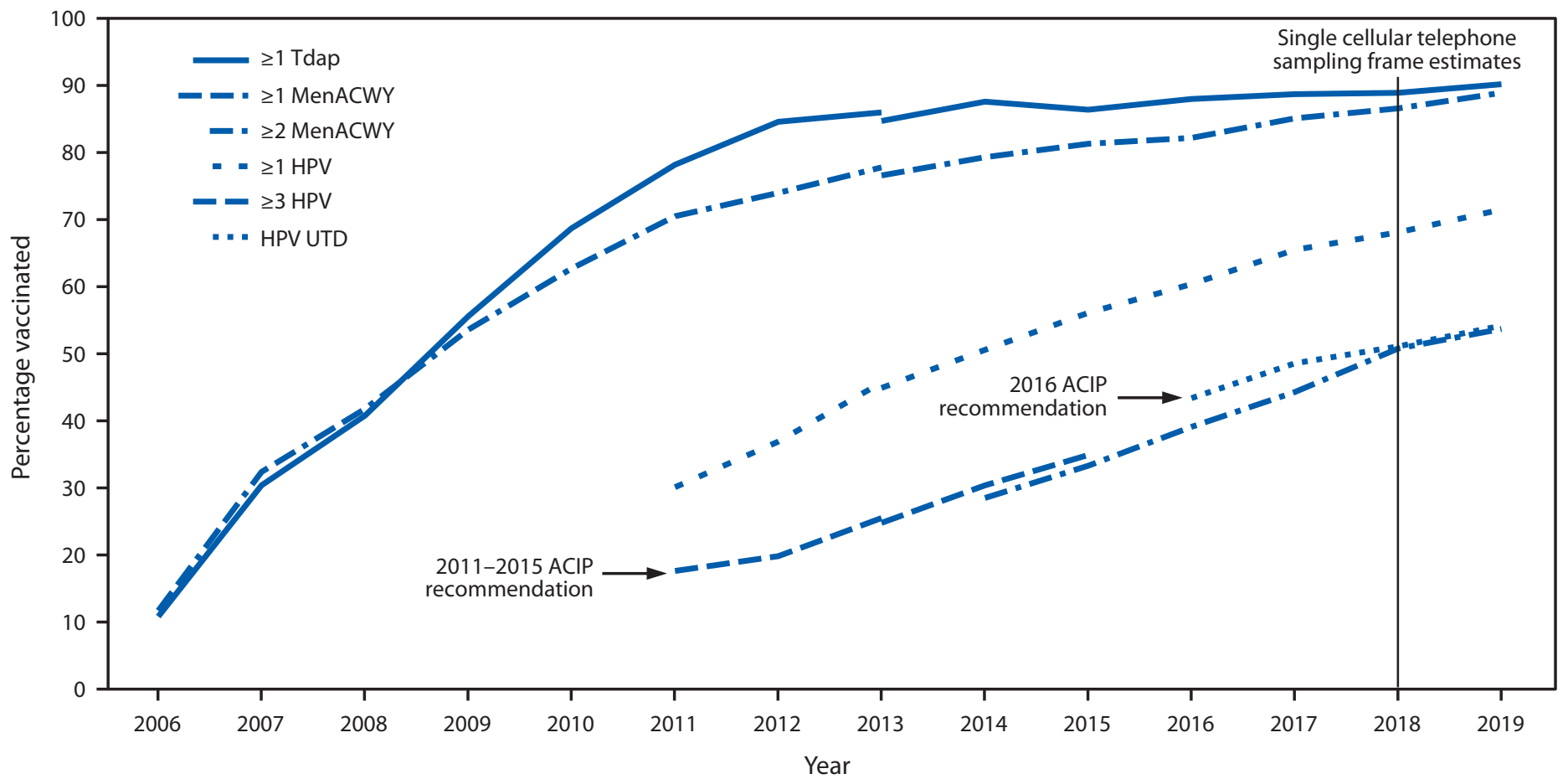

Abbreviations: HPV = human papillomavirus; MenACWY = quadrivalent meningococcal conjugate vaccine; Tdap = tetanus toxoid, reduced diphtheria toxoid, and acellular pertussis vaccine; UTD = up-to-date.

* $\geq 1$ dose Tdap at or after age 10 years; $\geq 1$ dose MenACWY or meningococcal-unknown type vaccine; $\geq 2$ doses MenACWY or meningococcal-unknown type vaccine, calculated only among adolescents aged 17 years at time of interview. Does not include adolescents who received their first and only dose of MenACWY at or after age 16 years; HPV vaccine, nine-valent (9vHPV), quadrivalent (4vHPV) or bivalent (2vHPV). The routine ACIP recommendation for HPV vaccination was made for females in 2006 and for males in 2011. Because HPV vaccination was recommended for boys in 2011, coverage for all adolescents was not measured before that year. HPV UTD includes those with $\geq 3$ doses, and those with 2 doses when the first HPV vaccine dose was initiated before age 15 years and at least 5 months minus 4 days elapsed between the first and second dose.

+ ACIP revised the recommended HPV vaccination schedule in late 2016. The recommendation changed from a 3-dose to 2-dose series with appropriate spacing between receipt of the first and second dose for immunocompetent adolescents initiating the series before the 15th birthday. Three doses are still recommended for adolescents initiating the series between the ages of 15 and 26 years. Because of the change in recommendation, the graph includes estimates for $\geq 3$ doses HPV from 2011 to 2015 and the HPV UTD estimate from 2016-2019. The routine ACIP recommendation for HPV vaccination was made for females in 2006 and for males in 2011. Because HPV vaccination was not recommended for males until 2011, coverage for all adolescents was not measured before that year.

$\S$ NIS-Teen implemented a revised adequate provider definition (APD) in 2014 and retrospectively applied that definition to 2013 data. Estimates using different APD definitions might not be directly comparable.

" NIS-Teen moved from a dual landline and cellular telephone sampling frame to a single cellular telephone sampling frame in 2018.

between socioeconomic status and geographic disparities and the barriers that might be contributing to such differences.

The findings in this report are subject to at least two limitations. First, the CASRO response rate to NIS-Teen was $19.7 \%$, and only $44.0 \%$ of households with completed interviews had adequate provider data. A portion of the questionnaires sent to vaccination provider(s) to request the adolescent's vaccination history were mailed in early 2020. A lower response rate was observed for those requests, likely because of the effect of the COVID-19 pandemic on health care provider operations. ${ }^{\dagger+\dagger \dagger}$ Second, even with adjustments for household and provider t†t† The Provider Record Check (PRC) phase of the NIS, which is conducted in Chicago, was disrupted on March 21, 2020, by a COVID-19-related stay-at-home order issued by the State of Illinois. This disruption meant that some 2019 NIS-Teen data received from responding providers could not be processed and resulted in a lower rate of adolescents with adequate provider data in Quarter 4 among those with consent to contact vaccination providers. NORC at the University of Chicago (https://www.norc.org), the NIS contractor, assessed the effect of the early close of the PRC operation. They found the adequate provider data rate was lower in Quarter 4 than in previous quarters, but that did not affect the demographics of children with adequate provider data or vaccination coverage estimates for MenACWY or HPV vaccines. Logistic regression models indicate that, after controlling for demographic covariates, the odds of being vaccinated with tetanus toxoid, reduced diphtheria toxoid, and acellular pertussis vaccine (Tdap) were lower in Quarter 4 compared with previous quarters, but the effect on the vaccination coverage rate estimate itself was minor. 
TABLE 2. Estimated vaccination coverage with selected vaccines and doses among adolescents aged $13-17^{*}$ years, by metropolitan statistical area $(\mathrm{MSA})^{\dagger}$ and by poverty level — National Immunization Survey-Teen (NIS-Teen), United States, 2019

\begin{tabular}{|c|c|c|c|c|c|c|c|c|c|}
\hline \multirow[b]{2}{*}{ Vaccine } & \multicolumn{3}{|c|}{$\begin{array}{c}\text { MSA } \\
\%(95 \% \mathrm{Cl})^{\S}\end{array}$} & \multicolumn{3}{|c|}{$\begin{array}{c}\text { Below poverty level } \\
\%(95 \% \mathrm{CI})^{\S}\end{array}$} & \multicolumn{3}{|c|}{$\begin{array}{c}\text { At or above poverty level } \\
\%(95 \% \mathrm{Cl})^{\S}\end{array}$} \\
\hline & $\begin{array}{l}\text { Non-MSA } \\
(n=3,689)\end{array}$ & $\begin{array}{c}\text { MSA } \\
\text { nonprincipal } \\
\text { city } \\
(n=7,745)\end{array}$ & $\begin{array}{c}\text { MSA } \\
\text { principal } \\
\text { city } \\
(n=7,354)\end{array}$ & $\begin{array}{l}\text { Non-MSA } \\
(n=607)\end{array}$ & $\begin{array}{c}\text { MSA } \\
\text { nonprincipal } \\
\text { city } \\
(n=820)\end{array}$ & $\begin{array}{c}\text { MSA } \\
\text { principal } \\
\text { city } \\
(n=1,376)\end{array}$ & $\begin{array}{l}\text { Non-MSA } \\
(n=2,962)\end{array}$ & $\begin{array}{c}\text { MSA } \\
\text { nonprincipal } \\
\text { city } \\
(n=6,676)\end{array}$ & $\begin{array}{c}\text { MSA } \\
\text { principal } \\
\text { city } \\
(n=5,687)\end{array}$ \\
\hline $\operatorname{Tdap}^{\mathbb{q}} \geq 1$ dose & $\begin{array}{c}88.7 \\
(86.7-90.5)\end{array}$ & $\begin{array}{c}90.5 \\
(89.0-91.8)\end{array}$ & $\begin{array}{c}90.2 \\
(88.5-91.7)\end{array}$ & $\begin{array}{c}92.2 \\
(88.7-94.6)\end{array}$ & $\begin{array}{c}87.6 \\
(80.3-92.4)\end{array}$ & $\begin{array}{c}88.9 \\
(86.0-91.3)\end{array}$ & $\begin{array}{c}88.0 \\
(85.6-90.1)\end{array}$ & $\begin{array}{c}90.9 \\
(89.5-92.1)\end{array}$ & $\begin{array}{c}90.6 \\
(88.4-92.4)\end{array}$ \\
\hline $\begin{array}{l}\text { MenACWY** } \\
\geq 1 \text { dose }\end{array}$ & $\begin{array}{c}83.5 \\
(80.9-85.8)^{\dagger+}\end{array}$ & $\begin{array}{c}90.3 \\
(89.1-91.4)\end{array}$ & $\begin{array}{c}88.6 \\
(86.8-90.2)\end{array}$ & $\begin{array}{c}90.4 \\
(87.0-93.0)\end{array}$ & $\begin{array}{c}92.4 \\
(88.5-95.1)\end{array}$ & $\begin{array}{c}88.3 \\
(84.6-91.1)\end{array}$ & $\begin{array}{c}82.2 \\
(79.0-85.0)^{\dagger \dagger}\end{array}$ & $\begin{array}{c}89.7 \\
(88.4-90.9)\end{array}$ & $\begin{array}{c}88.8 \\
(86.5-90.7)\end{array}$ \\
\hline$\geq 2$ doses $^{\S \S}$ & $\begin{array}{c}46.6 \\
(39.2-54.2)\end{array}$ & $\begin{array}{c}55.5 \\
(49.9-61.0)\end{array}$ & $\begin{array}{c}53.3 \\
(46.9-59.5)\end{array}$ & $\begin{array}{c}36.5 \\
(23.5-51.8)^{+\dagger}\end{array}$ & $\begin{array}{c}51.5 \\
(33.4-69.3)\end{array}$ & $\begin{array}{c}59.5 \\
(47.9-70.2)\end{array}$ & $\begin{array}{c}48.8 \\
(40.1-57.5)\end{array}$ & $\begin{array}{c}57.1 \\
(51.6-62.4)\end{array}$ & $\begin{array}{c}50.8 \\
(43.3-58.3)\end{array}$ \\
\hline \multicolumn{10}{|l|}{ HPVๆศ vaccine } \\
\hline$\geq 1$ dose & $\begin{array}{c}64.2 \\
(61.2-67.2)^{\dagger \dagger}\end{array}$ & $\begin{array}{c}71.2 \\
(69.2-73.1)\end{array}$ & $\begin{array}{c}73.8 \\
(71.5-75.9)\end{array}$ & $\begin{array}{c}72.6 \\
(66.8-77.7)\end{array}$ & $\begin{array}{c}75.2 \\
(67.9-81.3)\end{array}$ & $\begin{array}{c}76.5 \\
(71.4-81.0)\end{array}$ & $\begin{array}{c}62.6 \\
(59.0-66.1)^{\dagger \dagger}\end{array}$ & $\begin{array}{c}70.3 \\
(68.3-72.2)\end{array}$ & $\begin{array}{c}72.4 \\
(69.8-74.9)\end{array}$ \\
\hline HPV UTD*** & $\begin{array}{c}47.3 \\
(44.2-50.4)^{t+}\end{array}$ & $\begin{array}{c}53.4 \\
(51.2-55.7)^{\dagger \dagger}\end{array}$ & $\begin{array}{c}57.1 \\
(54.6-59.5)\end{array}$ & $\begin{array}{c}54.6 \\
(48.4-60.7)\end{array}$ & $\begin{array}{c}58.8 \\
(51.2-66.0)\end{array}$ & $\begin{array}{c}58.8 \\
(53.5-63.9)\end{array}$ & $\begin{array}{c}45.4 \\
(41.8-49.1)^{\dagger \dagger}\end{array}$ & $\begin{array}{c}52.7 \\
(50.3-55.0)^{\dagger+}\end{array}$ & $\begin{array}{c}56.5 \\
(53.6-59.4)\end{array}$ \\
\hline \multicolumn{10}{|l|}{ Females } \\
\hline$\geq 1$ dose & $\begin{array}{c}66.3 \\
(61.7-70.7)^{\dagger+}\end{array}$ & $\begin{array}{c}72.3 \\
(69.5-75.0)\end{array}$ & $\begin{array}{c}75.9 \\
(72.9-78.7)\end{array}$ & $\begin{array}{c}76.2 \\
(67.3-83.3)\end{array}$ & $\begin{array}{c}73.0 \\
(61.2-82.2)\end{array}$ & $\begin{array}{c}78.4 \\
(72.4-83.4)\end{array}$ & $\begin{array}{c}64.0 \\
(58.5-69.2)^{\dagger+}\end{array}$ & $\begin{array}{c}72.2 \\
(69.6-74.7)\end{array}$ & $\begin{array}{c}75.0 \\
(71.3-78.4)\end{array}$ \\
\hline HPV UTD & $\begin{array}{c}49.0 \\
(44.6-53.5)^{\dagger+}\end{array}$ & $\begin{array}{c}56.1 \\
(53.0-59.2)\end{array}$ & $\begin{array}{c}59.4 \\
(55.7-63.1)\end{array}$ & $\begin{array}{c}60.1 \\
(51.0-68.4)\end{array}$ & $\begin{array}{c}58.3 \\
(47.3-68.4)\end{array}$ & $\begin{array}{c}60.2 \\
(53.3-66.7)\end{array}$ & $\begin{array}{c}45.6 \\
(40.6-50.7)^{\dagger \dagger}\end{array}$ & $\begin{array}{c}55.3 \\
(52.1-58.4)\end{array}$ & $\begin{array}{c}58.7 \\
(54.2-63.1)\end{array}$ \\
\hline \multicolumn{10}{|l|}{ Males } \\
\hline$\geq 1$ dose & $\begin{array}{c}62.4 \\
(58.2-66.4)^{\dagger+}\end{array}$ & $\begin{array}{c}70.2 \\
(67.4-72.9)\end{array}$ & $\begin{array}{c}71.4 \\
(68.2-74.5)\end{array}$ & $\begin{array}{c}69.4 \\
(61.5-76.4)\end{array}$ & $\begin{array}{c}77.5 \\
(68.6-84.4)\end{array}$ & $\begin{array}{c}74.8 \\
(66.5-81.6)\end{array}$ & $\begin{array}{c}61.3 \\
(56.4-66.1)^{\dagger \dagger}\end{array}$ & $\begin{array}{c}68.6 \\
(65.6-71.5)\end{array}$ & $\begin{array}{c}69.6 \\
(65.9-73.1)\end{array}$ \\
\hline HPV UTD & $\begin{array}{c}45.7 \\
(41.3-50.1)^{\dagger+}\end{array}$ & $\begin{array}{c}51.0 \\
(47.7-54.3)\end{array}$ & $\begin{array}{c}54.6 \\
(51.4-57.8)\end{array}$ & $\begin{array}{c}49.8 \\
(41.4-58.3)\end{array}$ & $\begin{array}{c}59.4 \\
(48.7-69.3)\end{array}$ & $\begin{array}{c}57.5 \\
(49.6-65.1)\end{array}$ & $\begin{array}{c}45.2 \\
(40.0-50.5)^{\dagger \dagger}\end{array}$ & $\begin{array}{c}50.5 \\
(47.0-53.9)\end{array}$ & $\begin{array}{c}54.1 \\
(50.5-57.7)\end{array}$ \\
\hline MMR $\geq 2$ doses & $\begin{array}{c}91.7 \\
(90.0-93.1)\end{array}$ & $\begin{array}{c}92.3 \\
(91.0-93.3)\end{array}$ & $\begin{array}{c}91.4 \\
(89.3-93.2)\end{array}$ & $\begin{array}{c}91.6 \\
(87.6-94.4)\end{array}$ & $\begin{array}{c}93.7 \\
(90.3-95.9)\end{array}$ & $\begin{array}{c}93.6 \\
(91.6-95.1)\end{array}$ & $\begin{array}{c}91.9 \\
(90.0-93.5)\end{array}$ & $\begin{array}{c}92.2 \\
(90.8-93.4)\end{array}$ & $\begin{array}{c}91.0 \\
(88.0-93.2)\end{array}$ \\
\hline $\begin{array}{l}\text { Hepatitis A vaccine } \\
\geq 2 \text { doses }\end{array}$ & $\begin{array}{c}67.4 \\
(64.5-70.2)^{\dagger+}\end{array}$ & $\begin{array}{c}77.1 \\
(75.1-78.9)\end{array}$ & $\begin{array}{c}79.8 \\
(77.6-81.9)\end{array}$ & $\begin{array}{c}65.5 \\
(59.0-71.4)^{\dagger+}\end{array}$ & $\begin{array}{c}82.2 \\
(77.0-86.5)\end{array}$ & $\begin{array}{c}81.1 \\
(77.1-84.5)\end{array}$ & $\begin{array}{c}68.1 \\
(64.8-71.3)^{\dagger \dagger}\end{array}$ & $\begin{array}{c}76.9 \\
(74.9-78.9)\end{array}$ & $\begin{array}{c}79.6 \\
(76.9-82.1)\end{array}$ \\
\hline $\begin{array}{l}\text { Hepatitis B vaccine } \\
\geq 3 \text { doses }\end{array}$ & $\begin{array}{c}92.5 \\
(90.9-93.9)\end{array}$ & $\begin{array}{c}92.0 \\
(90.6-93.2)\end{array}$ & $\begin{array}{c}90.9 \\
(88.9-92.6)\end{array}$ & $\begin{array}{c}92.8 \\
(89.4-95.1)\end{array}$ & $\begin{array}{c}92.6 \\
(89.2-95.0)\end{array}$ & $\begin{array}{c}91.0 \\
(88.1-93.2)\end{array}$ & $\begin{array}{c}92.7 \\
(90.8-94.2)\end{array}$ & $\begin{array}{c}92.9 \\
(91.6-93.9)\end{array}$ & $\begin{array}{c}91.4 \\
(88.7-93.5)\end{array}$ \\
\hline Varicella & & & & & & & & & \\
\hline $\begin{array}{l}\text { History of } \\
\text { varicella§§§ }\end{array}$ & $\begin{array}{c}12.4 \\
(10.3-15.0)^{\dagger \dagger}\end{array}$ & $\begin{array}{c}8.3 \\
(7.3-9.3)\end{array}$ & $\begin{array}{c}9.3 \\
(8.1-10.6)\end{array}$ & $\begin{array}{c}9.8 \\
(7.1-13.4)\end{array}$ & $\begin{array}{c}8.2 \\
(5.9-11.2)^{\dagger \dagger}\end{array}$ & $\begin{array}{c}12.3 \\
(9.5-15.6)\end{array}$ & $\begin{array}{c}13.0 \\
(10.3-16.3)^{\dagger+}\end{array}$ & $\begin{array}{c}7.8 \\
(6.8-8.9)\end{array}$ & $\begin{array}{c}8.2 \\
(7.0-9.6)\end{array}$ \\
\hline \multicolumn{10}{|c|}{ No history of varicella disease } \\
\hline$\geq 1$ dose vaccine & $\begin{array}{c}95.0 \\
(93.4-96.2)\end{array}$ & $\begin{array}{c}95.6 \\
(94.6-96.4)\end{array}$ & $\begin{array}{c}94.7 \\
(92.9-96.1)\end{array}$ & $\begin{array}{c}95.7 \\
(92.4-97.6)\end{array}$ & $\begin{array}{c}95.0 \\
(91.9-97.0)\end{array}$ & $\begin{array}{c}95.2 \\
(93.2-96.6)\end{array}$ & $\begin{array}{c}95.2 \\
(93.4-96.5)\end{array}$ & $\begin{array}{c}95.6 \\
(94.5-96.4)\end{array}$ & $\begin{array}{c}94.8 \\
(92.3-96.6)\end{array}$ \\
\hline$\geq 2$ doses vaccine & $\begin{array}{c}90.9 \\
(89.1-92.4)\end{array}$ & $\begin{array}{c}91.4 \\
(90.2-92.6)\end{array}$ & $\begin{array}{c}89.6 \\
(87.1-91.6)\end{array}$ & $\begin{array}{c}90.7 \\
(86.2-93.9)\end{array}$ & $\begin{array}{c}93.0 \\
(89.6-95.4)\end{array}$ & $\begin{array}{c}92.9 \\
(90.7-94.6)\end{array}$ & $\begin{array}{c}91.3 \\
(89.2-93.0)\end{array}$ & $\begin{array}{c}91.0 \\
(89.6-92.3)\end{array}$ & $\begin{array}{c}89.1 \\
(85.8-91.6)\end{array}$ \\
\hline $\begin{array}{l}\text { Varicella disease } \\
\text { or received } \\
\geq 2 \text { varicella } \\
\text { vaccine doses }\end{array}$ & $\begin{array}{c}92.0 \\
(90.4-93.4)\end{array}$ & $\begin{array}{c}92.1 \\
(91.0-93.2)\end{array}$ & $\begin{array}{c}90.5 \\
(88.3-92.4)\end{array}$ & $\begin{array}{c}91.6 \\
(87.6-94.5)\end{array}$ & $\begin{array}{c}93.6 \\
(90.4-95.7)\end{array}$ & $\begin{array}{c}93.7 \\
(91.8-95.2)\end{array}$ & $\begin{array}{c}92.4 \\
(90.6-93.9)\end{array}$ & $\begin{array}{c}91.7 \\
(90.4-92.9)\end{array}$ & $\begin{array}{c}90.0 \\
(86.9-92.3)\end{array}$ \\
\hline
\end{tabular}

Abbreviations: $\mathrm{Cl}=$ confidence interval; $\mathrm{HPV}=$ human papillomavirus; MenACWY = quadrivalent meningococcal conjugate vaccine; $\mathrm{MMR}=$ measles, mumps, and rubella vaccine; Tdap = tetanus toxoid, reduced diphtheria toxoid, and acellular pertussis vaccine; UTD = up-to-date.

* Adolescents ( $N=18,788)$ in the 2019 NIS-Teen were born January 2001 through February 2007.

${ }^{\dagger}$ MSA status was determined by household-reported county of residence and was grouped into three categories: MSA principal city, MSA nonprincipal city, and non-MSA. MSA and principal city were as defined by the U.S. Census Bureau (https://www.census.gov/programs-surveys/metro-micro/about.html). Non-MSA areas include urban populations not located within an MSA and completely rural areas.

$\S$ Estimates with $95 \% \mathrm{Cls}>20$ might not be reliable.

I Includes percentages receiving Tdap at age $\geq 10$ years.

** Includes percentages receiving MenACWY and meningococcal-unknown type vaccine.

t+ Statistically significant difference $(p<0.05)$ in estimated vaccination coverage by MSA; referent group was adolescents living in MSA principal city areas.

$\S \S \geq 2$ doses of MenACWY or meningococcal-unknown type vaccine. Calculated only among adolescents aged 17 years at interview. Does not include adolescents who received 1 dose of MenACWY at age $\geq 16$ years.

१ๆी HPV vaccine, nine-valent (9vHPV), quadrivalent (4vHPV), or bivalent (2vHPV) in females and males combined.

*** HPV UTD includes those with $\geq 3$ doses and those with 2 doses when the first HPV vaccine dose was initiated before age 15 years and there was at least 5 months minus 4 days between the first and second dose. This update to the HPV recommendation occurred in December of 2016.

${ }^{t+\dagger}$ In July 2020, ACIP revised recommendations for hepatitis A vaccination to include catch-up vaccination for children and adolescents aged 2-18 years who have not previously received hepatitis A vaccine at any age (http://dx.doi.org/10.15585/mmwr.rr6905a1).

$\S \S$ By parent/guardian report or provider records. 
nonresponse, landline-only households, and phoneless house-

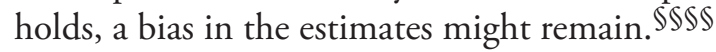

The COVID-19 pandemic has the potential to offset historically high vaccination coverage with Tdap and MenACWY and to reverse gains made in HPV vaccination coverage. Orders for adolescent vaccines have decreased among VFC providers during the pandemic. A recent analysis using VFC provider ordering data showed a decline in vaccine orders for several VFC-funded noninfluenza childhood vaccines since midMarch when COVID-19 was declared a national emergency (7). CDC, along with other national health organizations, continues to stress the importance of well-child visits and vaccinations as essential services (8). The majority of practices appear to be open and resuming vaccination activities for their pediatric patients $(9,10)$. Providers can take several steps to ensure that adolescents are up to date with recommended vaccines. These include 1) promoting well-child and vaccination visits; 2) following guidance on safely providing vaccinations during the COVID-19 pandemic 9999 ; 3 leveraging reminder and recall systems to remind parents of their teen's upcoming appointment, and recalling those who missed appointments and vaccinations; and 4) educating eligible patients and parents, especially those who might have lost employer-funded insurance benefits, about the availability of publicly funded vaccines through the VFC program. In addition, state, local, and territorial immunization programs can consider using available immunization information system data ${ }^{* * * * *}$ to identify local areas and sociodemographic groups at risk for undervaccination related to the pandemic, and to help prioritize resources aimed at improving adolescent vaccination coverage.

\footnotetext{
$\overline{\$ S \$ \$}$ An assessment of validity of the 2018 NIS-Teen estimates has been reported (https://www.cdc.gov/vaccines/imz-managers/nis/downloads/NIS-TEENPUF18-DUG.pdf, pages 62-69). NIS-Teen vaccination coverage estimates tended to be slightly low compared with true values derived after adjusting for noncoverage, nonresponse, and vaccination under-ascertainment, reaching up to 5.7 percentage points too low for Tdap. This was primarily attributed to under-ascertainment of vaccinations by the NIS provider record check. The validity of estimates did not change from 2017 to 2018 .

9999 https://www.cdc.gov/vaccines/pandemic-guidance/index.html.

***** https://repository.immregistries.org/files/resources/5bae51a16a09c/ identifying_immunization_pockets_of_need-_final3.pdf.

Corresponding author: Laurie D. Elam-Evans, LXE1@cdc.gov, 404-718-4838.
}

\footnotetext{
${ }^{1}$ Immunization Services Division, National Center for Immunization and Respiratory Diseases, CDC; ${ }^{2}$ Oak Ridge Institute for Science and Education, Oak Ridge, Tennessee; ${ }^{3}$ Division of Viral Diseases, National Center for Immunization and Respiratory Diseases, CDC; ${ }^{4}$ Leidos Health, Inc., Atlanta, Georgia; ${ }^{5}$ Division of Bacterial Diseases, National Center for Immunization and Respiratory Diseases, CDC.
}

All authors have completed and submitted the International Committee of Medical Journal Editors form for disclosure of potential conflicts of interest. No potential conflicts of interest were disclosed.

\section{Summary}

What is already known about this topic?

Three vaccines are routinely recommended for adolescents to prevent diseases that include pertussis, meningococcal disease, and cancers caused by human papillomavirus (HPV).

What is added by this report?

Adolescent vaccination coverage in the United States continues to improve for HPV and for meningococcal vaccines, with some disparities. Among adolescents living at or above the poverty level, those living outside a metropolitan statistical area (MSA) had lower coverage with HPV and meningococcal vaccines than did those living in MSA principal cities.

What are the implications for public health care?

Ensuring routine immunization services for adolescents, even during the COVID-19 pandemic, is essential to continuing progress in protecting individuals and communities from vaccine-preventable diseases and outbreaks.

\section{References}

1. Robinson CL, Bernstein H, Poehling K, Romero JR, Szilagyi P. Advisory Committee on Immunization Practices recommended immunization schedule for children and adolescents aged 18 years or younger-United States, 2020. MMWR Morb Mortal Wkly Rep 2020;69:130-2. https:// doi.org/10.15585/mmwr.mm6905a3

2. Meites E, Kempe A, Markowitz LE. Use of a 2-dose schedule for human papillomavirus vaccination - updated recommendations of the Advisory Committee on Immunization Practices. MMWR Morb Mortal Wkly Rep 2016;65:1405-8. https://doi.org/10.15585/mmwr.mm6549a5

3. Walker TY, Elam-Evans LD, Yankey D, et al. National, regional, state, and selected local area vaccination coverage among adolescents aged 13-17 years-United States, 2018. MMWR Morb Mortal Wkly Rep 2019;68:718-23. https://doi.org/10.15585/mmwr.mm6833a2

4. Monnat SM, Rhubart DC, Wallington SF. Differences in human papillomavirus vaccination among adolescent girls in metropolitan versus non-metropolitan areas: considering the moderating roles of maternal socioeconomic status and health care access. Matern Child Health J 2016;20:315-25.https://www.ncbi.nlm.nih.gov/entrez/query.fcgi?cmd =Retrieve\&db=PubMed\&list_uids=26511129\&dopt=Abstract https:// doi.org/10.1007/s10995-015-1831-x

5. Henry KA, Swiecki-Sikora AL, Stroup AM, Warner EL, Kepka D. Areabased socioeconomic factors and human papillomavirus (HPV) vaccination among teen boys in the United States. BMC Public Health 2018;18:19. https://doi.org/10.1186/s12889-017-4567-2

6. Swiecki-Sikora AL, Henry KA, Kepka D. HPV vaccination coverage among US teens across the rural-urban continuum. J Rural Health 2019;35:506-17. https://doi.org/10.1111/jrh.12353

7. Santoli JM, Lindley MC, DeSilva MB, et al. Effects of the COVID-19 pandemic on routine pediatric vaccine ordering and administrationUnited States, 2020. MMWR Morb Mortal Wkly Rep 2020;69:591-3. https://doi.org/10.15585/mmwr.mm6919e2

8. CDC. Routine vaccination during the COVID-19 outbreak. Atlanta, GA: US Department of Health and Human Services, CDC; 2020. https://www.cdc.gov/vaccines/parents/visit/vaccination-duringCOVID-19.html 
9. Vogt TM, Zhang F, Banks M, et al. Provision of pediatric immunization services during the COVID-19 pandemic: an assessment of capacity among pediatric immunization providers participating in the Vaccines for Children program-United States, May 2020. MMWR Morb Mortal Wkly Rep 2020;69:859-63. https://doi.org/10.15585/mmwr. mm6927a2
10. Langdon-Embry M, Papadouka V, Cheng I, Almashhadani M, Ternier A, Zucker JR. Notes from the field: rebound in routine childhood vaccine administration following decline during the COVID-19 pandemicNew York City, March 1-June 20, 2020. MMWR Morb Mortal Wkly Rep 2020;69:999-1001. https://doi.org/10.15585/mmwr.mm6930a3 